\title{
Posterior arch anomalies of Atlas and its clinical significance
}

\author{
Mehta UK ${ }^{1}$, Geetha $\mathrm{KN}^{2}$, Gaikward $\mathrm{M}^{3}$, Chavan $\mathrm{L}^{4}$ \\ ${ }^{1}$ Dr Umesh Kumar Mehta, PG student ${ }^{2}$ Dr Geetha K N, Associate Professor, ${ }^{3}$ Dr Mrinalini Gaikward, Tutor, ${ }^{4}$ Dr Lalita \\ Chavan, Assistant Professor. All are affiliated with Department of Anatomy, MGM Medical College, MGM IHS, Navi \\ Mumbai, Maharashtra, India.
}

Correspondence Address: Dr. Geetha K N, Email: geetha.dr@gmail.com

\begin{abstract}
Introduction: Congenital anomalies of posterior arch of atlas are very rare. Most of the time detection of this developmental anomaly is incidental while investigating for neck pain and stiffness or injury involving the region of head and neck. Aim: Our aim was to determine the incidence of posterior arch anomaly of atlas in Maharashtra region. 75 dried human atlas vertebrae were included for this study. Observations: We detected Type A and B in our study. Results: The incidence of posterior arch anomaly is $4 \%$ i.e. 3 out of 75 vertebrae. We detected Type A and B in our study and these types are generally asymptomatic. Type $\mathrm{C}$ to $\mathrm{E}$ may be associated with neurological deficit. Conclusion: It is essential for the clinicians to recognize the condition and the specific type of anomaly in order to distinguish it from fractures secondary to trauma and for the proper guidance of the patients accordingly.
\end{abstract}

Key words: Atlas vertebra, Congenital anomaly, Posterior arch, Clinical significance.

\section{Introduction}

Congenital anomalies of the Atlas (C 1) vertebra are uncommon, but well documented. There are many case reports related to this type of malformation in the literature and exhibit a wide range of anomalies including aplasia, hypoplasia and various arch defects [1]

The embryological development of the first two cervical vertebrae is complicated and differs from that of typical vertebrae. The atlas is formed by the caudal half of occipital somite 4 and the cranial half of cervical somite 1 [2]. Atlas is commonly ossified from three centres (Figure 1), one for the anterior arch and two for the lateral masses, which appear by $7^{\text {th }}$ week of intrauterine life. Lateral masses extend postero-medially and fuse in the midline to form the posterior arch by 3-5 years of age [1$6]$. Anterior centre fuses with the two lateral centers between 5 to 9 years of age [2].

Manuscript received: $10^{\text {st }}$ July 2014

Reviewed: $20^{\text {th }}$ July 2014

Author Corrected: $30^{\text {th }}$ July 2014

Accepted for Publication: $31^{\text {st }}$ July 2014

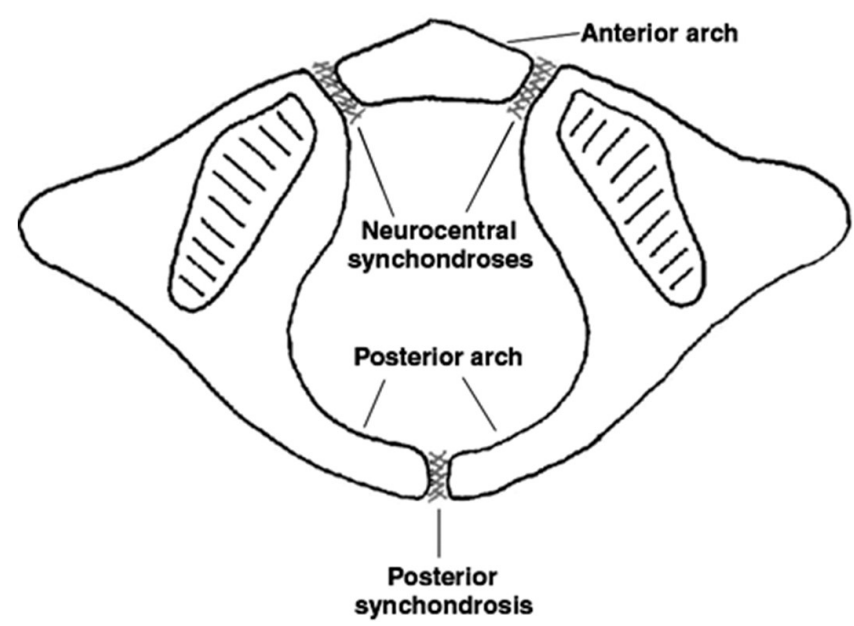

Figure 1: Ossification centres of Atlas vertebrae [7] 
A failure of chondrogenesis in this phase results in posterior arch defects which range from a simple cleft to complete absence of the entire posterior arch. About $2 \%$ of the population shows an additional ossification centre in the midline during second year of life, which forms the posterior tubercle of the atlas [2, 4, 5]. Failure of fusion or absence of fourth ossification center leads to clefts or aplasia of the posterior arch. Posterior arch forms about $3 / 5^{\text {th }}$ of the atlantal ring [8].

Currarino et al [9] have proposed an anatomical classification of congenital anomalies of atlas (Figure: 2), modified from Von Torks and Gehle [3]. The congenital anomalies of posterior arch of atlas is sub divided into 5 types

Type A: Failure of posterior midline fusion of the 2 hemi arches. Commonly appear as a fissure or a small gap in the midline.

Type B: Unilateral cleft. A defect is present on one side, which ranges from a small cleft to complete absence of one half of the arch.

Type C: Bilateral cleft with persistent dorsal part of arch.

Type D: Absence of posterior arch with persistent posterior tubercle.

Type E: Absence of entire posterior arch

\section{A}<smiles>c1ccc2ccccc2c1</smiles>

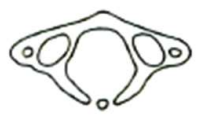

\section{B}
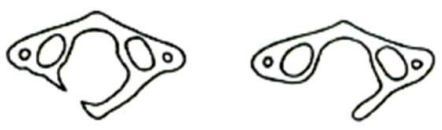

C
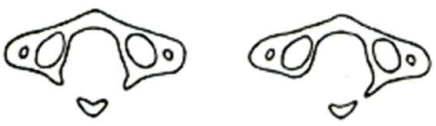

D
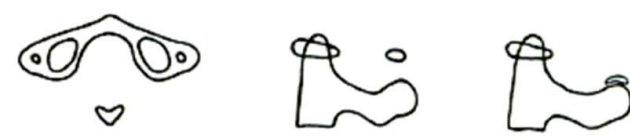

E
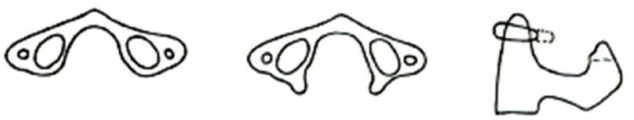

Figure 2: Classification of Congenital anomalies of posterior arch of atlas [9]

Our aim was to determine the incidence of posterior arch anomaly of atlas in Maharashtra region. Knowledge of different types of posterior arch anomaly of atlas is significant to orthopaedic and neurosurgeons. It is important to identify the exact type of malformation to determine the clinical significance and to prevent subsequent neurological complications.

\section{Material and Methods}

A total of 75 of dried adult human atlas vertebrae of unknown sex and age were studied from the collection in the department of Anatomy, Government medical college, Aurangabad, Maharashtra, India.

Method: This is an observational study. Each atlas vertebra was observed for morphological variations; specifically more attention was given to the morphology of posterior arch.

\section{Observation and Results}

We observed Type A and Type B anomalies in 3 vertebrae 


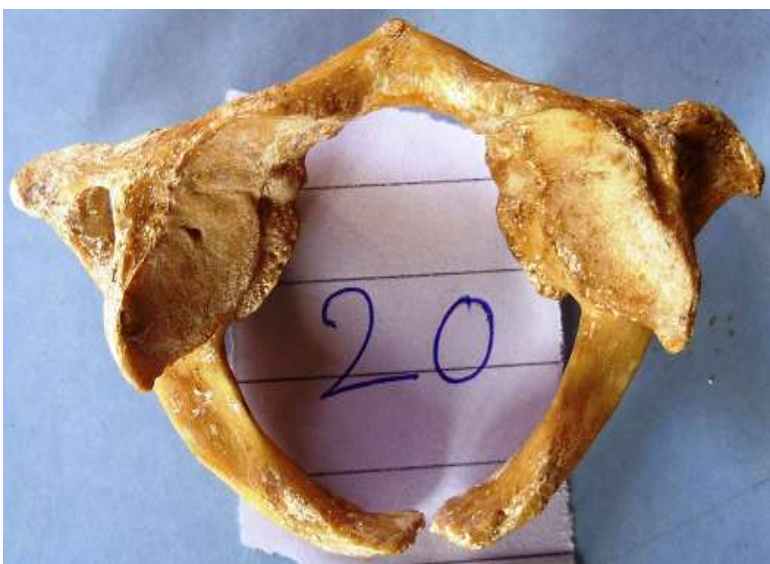

Figure 3: Type A anomaly- Posterior median deficiency/cleft
Research Article

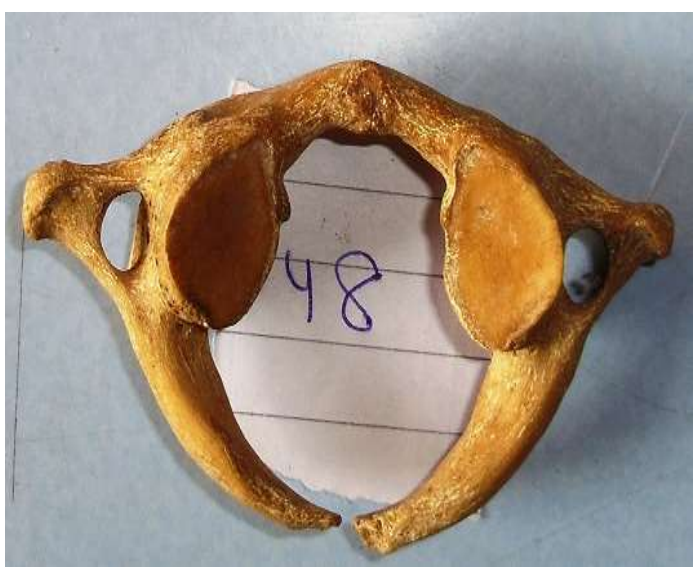

Figure 4: Type A anomaly - Posterior median deficiency/cleft

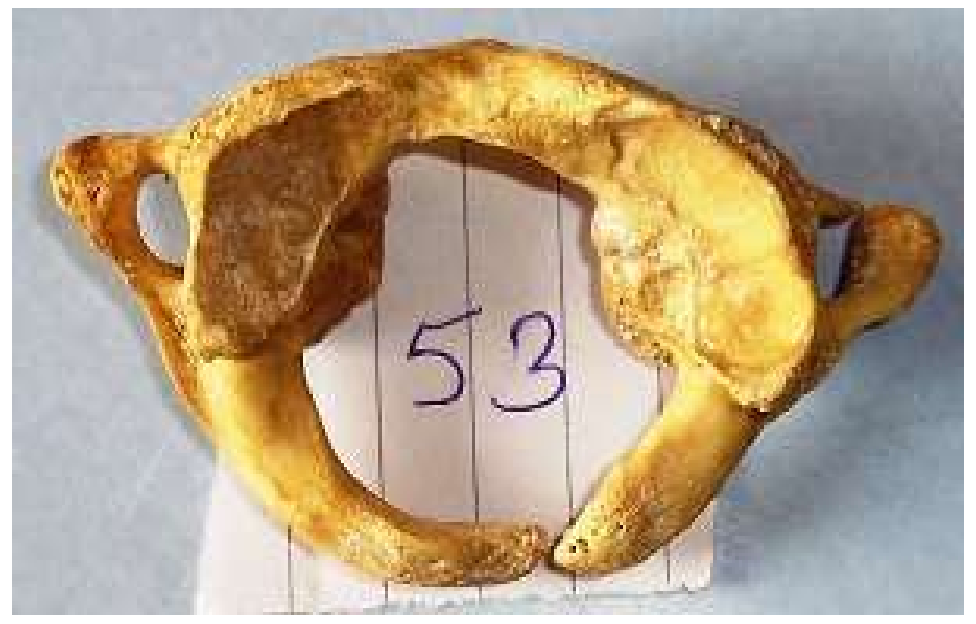

Figure 5: Type B anomaly - Right para-median deficiency/cleft

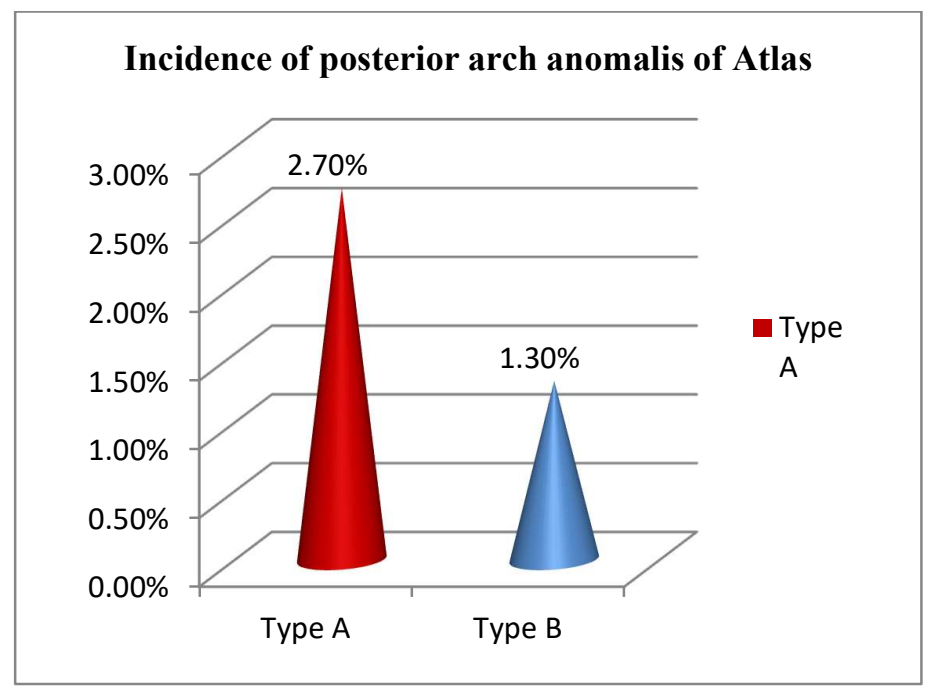

Chart 1: Incidence of posterior arch anomalies in the present study

Total incidence of posterior arch anomaly of atlas in this study is $4 \%$. 


\section{Discussion}

Many theories have been put forth to explain the exact cause of congenital anomalies of atlas [2]. It may be associated with several disorders like Arnold - Chiari malformation, Klippel - Feil syndrome, Gonadal dysgenesis, Down syndrome and Turner syndrome [1, 2, 10-12]. Hereditary factors may contribute to their origin. Motateanu et al [1, 3, 4] have reported a case of affected mother and daughter and Currarino et al [9] have reported a case of affected mother and son, suggesting an autosomal inheritance.

Posterior arch defect is believed to occur as a result of localised defect in chondrification rather than a primary defect in ossification. This has been proved by autopsy and intra operative findings $[1,2]$

\section{1: Incidence of Posterior arch anomaly of Atlas (Table} No: 1)

Incidence of posterior arch anomaly of atlas varies from $0.69 \%$ to $4 \%$ in different anatomical and radiologic studies. According to Currarino et al [9] the incidence of posterior midline deficiency (Type A) is 3-4\% of all population and this comprise $97 \%$ of all posterior arch defects, and that of Type B-E is $0.69 \%$.

Other reported incidences are:
Senoglu M et al [13] studied 1354 cases ( CT scans of 1104 patients, 166 dried atlas and 84 autopsies) and the overall incidence of posterior arch anomaly was $3.32 \%$, in which Type A comprised 2.6\%, Type B $0.54 \%$ and Type E $0.18 \%$. There were no Type C and D anomaly in their study. Sebastian et al [14] (studied 1069 CT scans) and the incidence was $3.6 \%$, this comprises $92.7 \%$ of all cases of arch defects. Type A anomaly incidence was $3.2 \%$ and that of Type $\mathrm{B}$ and $\mathrm{C}$ was $0.2 \%$ of the population. There was no Type D and E defect. Parul koushal [15] reported an incidence of 3.3\% (one Type A anomaly out of 30 atlas vertebrae studied), Solomen et al [16] reported an incidence of $0.91 \%$ ( one Type E anomaly out of 109 atlas vertebrae studied), Giepel et al $[10,11]$ (performed 1613 autopsies ) reported an incidence of 4\%. Jong Kyn Kwon et al [10] (1153 CT scans analysed) incidence was $9.5 \%$. In their study Type A comprised $0.78 \%$ and type B $0.17 \%$. There was no type $\mathrm{C}$ to $\mathrm{E}$ anomalies.

In the present study out of 75 atlas vertebrae analysed 3 presented with posterior arch defect, two with Type A defect (Fig: $2 \& 3$ ) and one with Type B (Fig: 4) defect. The total incidence of posterior arch defect is $4 \%$ (Chart: $1)$.

Table 1: Comparison of present study with other authors: - Incidence of Different types of Posterior Arch Anomalies:

\begin{tabular}{|c|c|c|c|c|c|c|c|}
\hline Authors & $\begin{array}{l}\text { Year of } \\
\text { Study }\end{array}$ & Material & Type A & Type B & Type C & Type D & Type E \\
\hline Giepel $[10,11]$ & $1930-1935$ & Autopsy & $4 \%$ & - & $\ldots$ & - & - \\
\hline Currarino [9] & 1994 & CT Scan & $3-4 \%$ & \multicolumn{4}{|l|}{$0.69 \%$} \\
\hline $\begin{array}{l}\text { Jong Kyn Kwon } \\
{[10]}\end{array}$ & 2009 & CT Scan & $0.78 \%$ & $0.17 \%$ & - & - & - \\
\hline Senoglu M [13] & 2007 & $\begin{array}{l}\text { CT Scan, Bone, } \\
\text { Autopsy }\end{array}$ & $2.6 \%$ & $0.54 \%$ & - & - & $0.18 \%$ \\
\hline Parul Koushal [15] & 2011 & CT Scan & $3.3 \%$ & - & - & - & - \\
\hline $\begin{array}{l}\text { Sebastian Guenkel } \\
{[14]}\end{array}$ & 2013 & CT Scan & $3.2 \%$ & \multicolumn{2}{|l|}{$0.2 \%$} & - & - \\
\hline $\begin{array}{l}\text { Solomon } \\
\text { Krupanidhi [16] }\end{array}$ & 2013 & Bone & - & - & - & - & $0.91 \%$ \\
\hline Present Study & 2014 & Bone & $2.7 \%$ & $1.3 \%$ & - & - & - \\
\hline
\end{tabular}

Clinical significance of Atlas posterior arch anomalies Patients with posterior arch anomaly can be asymptomatic and the detection is incidental while investigating for neck pain and stiffness or trauma involving the head and neck region. Currarino et al [9] found that $1 / 3^{\text {rd }}$ of the affected patients are asymptomatic. Clinical presentation is variable depending upon the type of defect, compensatory mechanism and the presence or absence of atlanto-axial instability.

Dritan et al [1] reported a case of aplasia of posterior arch of atlas with intact posterior tubercle (Type D) associated with anterior arch rachischisis of axis vertebra and disc degeneration at C4-5 and C5-6 levels. Patient presented 
with neck pain and stiffness. The explanation given by the author for disc degeneration is, the altered stability of upper cervical segment spine resulting in increased strain to lower levels. Senoy et al [17] reported a case of bilateral cleft of posterior arch (Type C) and the presenting complain was occipital headache.

Aseem Sharma et al [18] reported 3 cases, one with Type $\mathrm{C}$ anomaly, presented with episodic weakness in all 4 limbs after trauma, second case with Type D anomaly, presented with weakness in both upper limbs and the third case with again Type $\mathrm{C}$ anomaly presented with neck pain and stiffness.

They were the first to demonstrate the inward movement of the posterior tubercle during extension of the cervical spine; this can impinge on spinal cord and later leads to compression of it.

EC Tan et al [5] reported a case of partial absence of posterior arch (Type B) associated with cleft in the anterior arch, presented with neck pain radiating to arm. Ji Won Choi et al [19] reported a case of Type D anomaly associated with compression of spinal cord during extension of neck, presented with tremor and hyperesthesia of lower limb after a minor head injury.

It was proposed that compression of spinal cord results secondary to inward movement of isolated posterior bony fragment during extension of neck in type $\mathrm{C}$ or $\mathrm{D}$ anomalies [3]. Abraham Berger et al [20] reported a case of Type D anomaly in which the patient presented with neck pain after trauma.

Corominas et al [9] reported a case of aplasia of posterior arch (Type E) and MRI in this case showed the existence of posterior ligament between $\mathrm{C} 1$ and $\mathrm{C} 2$ providing stability to this region. Based on this finding they suggested MRI to identify the presence of transverse atlanto- axial ligament between $\mathrm{C} 1$ and $\mathrm{C} 2$, absence of which can lead to atlanto - axial instability or transient quadriparesis.

Bony gap in the posterior arch in Type $\mathrm{D}$ and $\mathrm{E}$ is bridged by fibrous tissue extending from foramen magnum to axis vertebra and this was proved by autopsy and intraoperative findings. Sridhar et al [6] reported a case of 'floating' posterior tubercle in a 25 year old female with quadriparesis and they performed excision of posterior tubercle along with cervico - occipito fusion. Martin Torrani et al [12] reported a case of Type E anomaly associated with downward projection of the posterior border of the Foramen magnum.
In case of associated atlanto- axial instability, posterior fusion is the common procedure and if the posterior arch is deficient, the posterior fusion involves the occipital bone and the lower cervical segments.

\section{Conclusion}

The present study has found the incidence of congenital anomaly of posterior arch of atlas in Maharashtra region as $4 \%$. Congenital anomalies of posterior arch of atlas are rare but the Surgeons and Radiologist must be familiar with these types of anomalies. Type A and B can be mistaken for fractures mostly because these patients are asymptomatic and detection occurs as an incidental finding while investigating for some unrelated reasons.

Type $\mathrm{C}$ to $\mathrm{E}$ can be associated with various neurological problems and awareness of these anomalies is important to guide the patients and also for the surgical correction if required. Type $\mathrm{C}$ and $\mathrm{D}$ patients should be warned to avoid strenuous sports since these types of anomalies can be associated with atlato axial instability.

Future scope of this study: In most of the reported cases the affected patients are females and children. Whether this is due to the absence of neurological deficits in males as a result of some compensatory mechanism or there is actual sexual dimorphism in posterior arch anomaly, no clear answer to this till now. To provide an answer we need a large sample size study of dried atlas vertebrae of known sex and age.

Funding: No funding was received for this study.

Conflict of Interest: Authors declare that they have no conflict of interest

Permission from Institutional Research Board: Yes

\section{References}

1. Dritan Pasku, Pavlos Katonis, Apostolos Karantanas, Alexander Hadjipavlou. Congenital posterior atlas defect associated with anterior rachischisis and early cervical degenerative disc disease : A case study and review of the literature. Acta Orthop Belg. 2007;73:282-5.

2. Hakan Sabuncuoglu, Selcuk Ozdogan, Demet Karadag, Erdener Timurk Aynak. Congenital Hypoplasia of the Posterior Arch of the Atlas: Case Report and Extensive Review of the Literature. Turkish Neurosurgery. 2011;21(1):97-103

3. M H Schro"del, V Braun, E Stolpe HH. Coincidental deficiency of the posterior arch of the atlas and. Emerg Med J. 2005;22:526-8. 9. 
4. L. Corominas, K. Z. Masrouha. Case repot: Congenital absence of the posterior arch of the atlas associated with a fracture of the anterior arch. J bone Jt Surg. 2010;92:1300-2.

5. EC Tan, HC Soon, M Kevin, BC Se To. Congenital Absence of the Posterior Arch of the Atlas - A Strange but Benign Anomaly. Malaysian Orthop J. 2007;1(2):302 .

6. K. Sridhar, B.Jose . "Floating” posterior tubercle of atlas as a cause of cord contusion : Case report and review of the literature. Spinal Surgey. 1(1):60-2.

7. Joseph J. Junewick, Matthew S. Chin, Indu Rekha Meesa, Saima Ghori, S. Jemar Boynton, Charles R. Luttenton. Ossification Patterns of the Atlas Vertebra. AJR. 2011;197:1229-34.

8. Gupta, C., Radhakrishnan, P., Palimar, V., D'souza, AS, Kiruba NL. A quantitative analysis of atlas vertebrae and its abnormalities. J Morphol Sci . 2013;30(2):77-81.

9. Guido Currarino, Nancy Rollins, and Jan T. Diehl. Congenital Defects of the Posterior Arch of the Atlas : A Report of Seven Cases Including an Affected Mother and Son. AJNR. 1994;15:249-54.

10. Jong Kyu Kwon, Myoung Soo Kim, Ghi Jai Lee.. The Incidence and Clinical Implications of Congenital Defects of Atlantal Arch. J Korean Neurosurg Soc. 2009;46:522-7.

11. Kaijun Wang, Xia Li, Haiyan Lou, Benyan Luo. Recurrent attacks of headache and neck pain caused by congenital aplasia of the posterior arch of atlas in an adult. bmj Csae Reports. 2010;1-4.

12. Martin Torriani and José Leonardo Goes Lourenço. AGENESIS OF THE POSTERIOR ARCH OF THE ATLAS. Rev Hosp Clin Fac Med S. 2002;57(2):73-6.
13. Senoglu M, Safavi-Abbasi S, Theodore N, Bambakidis NC, Crawford NR SV. The frequency and clinical significance of congenital defects of the posterior and anterior arch of the atlas. J Neurosurg Spine. 2007;7:399-402. Google / ncbi)

14. Sebastian Guenkel, Sladjana Schlaepfer, Sonja Gordic, Guido A. Wanner, Hans-Peter Simmen and Clément M. L. Werner. Incidence and Variants of Posterior Arch Defects of the Atlas Vertebra. Radiol Res Pract. 2013;Article ID 957280, 3 pages.

15. Kaushal P. Median deficiency in the posterior arch of the atlas vertebra: a case report. Int $\mathrm{J}$ Anat Var. 2011;4:67-8.

16. U. Solomon Krupanidhi, Jayaprakash B.R, Mallikarjun M. and Raveendra Patil. Total aplasia of posterior arch of the Atlas. Int J Biomed Res. 2013;4:491 -493 .

17. Senay OZDOLAP, Selda SARIKAYA, Ozlem BALBALOGLU, Murat KALAYCI: a case Report. Congenital defects of posterior arch of the atlas : a case report. Neuroanatomy. 2007;6:72-4

18. Aseem Sharma, Shailesh B. Gaikwad, Parminder S. Deol, Nalin K. Mishra, and Shashank S. Kale. Case Report Partial Aplasia of the Posterior Arch of the Atlas with an Isolated Posterior Arch Remnant: Findings in Three Cases. AJNR Am J Neuroradiol. 2000;21:116771.

19. Ji Won Choi, Je Hoon Jeong, Seung Myung Moon, Hyung Sik Hwang. Congenital Cleft of Anterior Arch and Partial Aplasia of the Posterior Arch of the C1. J Korean Neurosurg Soc. 2011;49:178-81.

20. Abraham Berger, Nikolaos A. Alexandro. Congenital Absence of the Posterior Arch of the Atlas Associated with a Non-displaced Fracture of C2. Isr J Trauma, Intensice care Emerg Med. 2002;2(2):20-2.

\section{How to cite this article?}

Mehta UK, Geetha KN, Gaikward M, Chavan L. Posterior arch anomalies of Atlas and its clinical significance. Int J Med Res Rev 2014;2(4):361- 366. doi:10.17511/ijmrr.2014.i04.18 